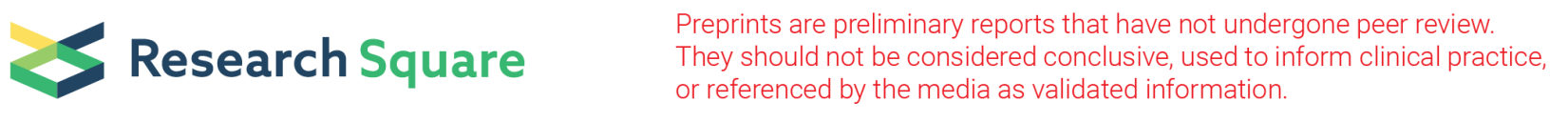

\title{
dentification of novel insulin resistance related ceRNA network: LncRNA, RP11-773H22.4; miR-3163, miR-1; mRNAs:RET , IGF1-R, m-TOR, GLUT-4, AKT2 in T2DM and its potential editing by CRISPR/Cas 9
}

Marwa Matboli

Ain Shams University

Marwa Mostafa Kamel

Ain Shams University

Nada Essawy

Institut Pasteur

Meram Mohamed Bekhit

Ain Shams University

Basant Abdulrahman

University of Calgary

Ghada Mohamed

Ain Shams University

Sanaa Eissa ( $\sim$ drsanaa_mohamed@med.asu.edu.eg )

Ain Shams University

Research Article

Keywords: Insulin resistance, IncRNA, miRNA, genes, gene editing, Diabetes Mellitus

Posted Date: March 23rd, 2021

DOI: https://doi.org/10.21203/rs.3.rs-258240/v1

License: @ (i) This work is licensed under a Creative Commons Attribution 4.0 International License. Read Full License 


\section{Abstract}

Background: In this study, we aimed to construct Insilco, a competing endogenous RNAs (ceRNAs) network linked to the pathogenesis of insulin resistance followed by its experimental validation in patients', matched control and cell line samples. And also, to evaluate the efficacy of CRISPR/Cas9 as a potential therapeutic strategy to modulate the expression of this deregulated network. By applying bioinformatic tools, we identified and verified a ceRNA network panel of IncRNA, miRNAs and mRNAs related to insulin resistance and then we validated its expression in 123 patients' and 106 matched controls and cell line samples using real time PCR.

Results: LncRNA-RP11-773H22.4, together with RET , IGF1-R and m-TOR mRNAs showed significant upregulation in T2DM compared with matched controls while miRNAs: miR-3163, miR-1 and mRNAs: GLUT-4 and AKT2 expression displayed marked downregulation in diabetic samples.Two guide RNAs were designed to target the sequence flanking LncRNA/miRNAs interaction by CRISPER/Cas9 in cell culture. Gene editing tool efficacy was assessed by measurement of the network downstream proteins, GLUT4 and mTOR by immunofluorescence. CRISPR/Cas9 successfully knockout LncRNA-RP11-773H22.4 as evidenced by the reversal of the gene expression of the identified network at RNA and protein levels to the normal expression pattern after gene editing.

Conclusion: The presented study provides the significance of this ceRNA based network and its related target genes panel both in the pathogenesis of insulin resistance and as a therapeutic target for gene editing in T2DM.

\section{Introduction}

Type 2 diabetes is a prevalent chronic metabolic disorder associated with resistance to insulin action and insufficient insulin secretion and represents a global continuously growing healthcare burden that is reported by the International Diabetes Federation (IDF) diabetes atlas ninth edition in 2019, as approximately 463 million adult (20-79 years old) are living with diabetes mellitus and this number is expected to increase to 700 million by 2045 1,2. Egypt, most notably, has topped the scale compared to other countries when it comes to the prevalence of DM. According to IDF, Egypt's diabetes prevalence (15.56\% in adults of 20-79 years of age with annual mortality of 86,478 deaths) has placed it on the top 10 list of countries in terms of the number of diabetics ${ }^{3}$.

A major focus of research nowadays is the different signaling pathways implicated in T2DM in order to develop novel therapeutic strategies for diabetes and its complications. Although T2DM is a multi-faceted disease with contributing genetic, epigenetic and environmental factors, the reduced sensitivity to insulin in target cells constitutes the hallmark of this disease ${ }^{4}$. Insulin resistance represents the major pathological process underlying the disease and involves a complex network of defects in signal transduction, such defects in insulin Receptor Substrate 1/2 (IRS-1/2), phosphatidylinositol 3-Kinase (PI3K)/Serine/Threonine Kinase (AKT) and Glucose Transporter 4 (GLUT4) ${ }^{5}$.

Epigenetics has been shown to be involved in the regulation of inflammation and cellular senescence, both of which are associated with type 2 diabetes. Abnormal epigenetic modifications including changes in non-coding RNA levels have been implicated in the pathogenesis of a myriad of diseases, notably diabetes. Studies postulate that RNAs affect the level of one another by competing for a small pool of micro RNAs, this is described as the competing endogenous RNA theory (ceRNA) and is supported by growing evidence in a number of diseases ${ }^{6}$. Long non-coding RNA (IncRNA) can act as a ceRNA influencing the post-transcriptional regulation. That's because they have miRNA binding sites and can affect miRNAs levels available for binding to their target mRNAs. Consequently, they abolish the repression of these mRNAs explaining their negative correlation with miRNA's expression ${ }^{7}$. There's a list of long noncoding RNAs linked to the development of T2DM, including HOTAIR, MEG3, LET and MALAT1 ${ }^{8}$. In addition to IncRNAs, many miRNAs are also implicated in the development of T2DM namely as miR-135, 202 and 214 along with their targets (Rock-1, Akt2, and Vamp2). In particular, miR-135 is involved in insulin resistance through its effect on insulin receptor substrate 1 (IRS-1) while miR-214 overexpression leads to Akt2 down regulation, resulting in subsequent defects in insulin stimulation of glucose transport and ultimately insulin resistance. This has been investigated in C2C12 and L6 cell line models of insulin resistance ${ }^{9}$.

Gene editing is a recent breakthrough with a considerable potential in understanding and treatment of several diseases. By the virtue of this technique, researchers could target predetermined parts of the DNA sequence and produce specific alterations including insertions, deletions, point mutations or translocations through the production of double-stranded breaks at target sites and as a result many DNA repair systems are activated. Gene editing efficiency significantly improved after the discovery of a novel tool extracted from Streptococcus pyogenes; CRISPR (clustered regularly interspaced short palindromic repeats)-associated protein-9 nuclease (Cas9), which led to a potentially low cost, time-saving of whole human genome editing (including non-coding RNAs) that are consistent with high throughput screening protocols ${ }^{10}$.

The present paper aimed to determine potential ceRNA panel related to insulin resistance from databases followed by the validation of its expression in both patients' clinical samples and lymphocyte cell lines. Besides, we called in question the role of this identified insulin resistance (IR) related panel in the pathogenesis of type 2 DM. Finally, we evaluated the efficacy of the gene editing tool CRISPR/Cas 9 as a potential therapeutic strategy to modulate the expression of this deregulated network in T2DM.

\section{Material And Methods}

\section{1 | Participants And Samples}

Participants were divided into the following groups; Group 1: 123 cases with type 2 diabetes mellitus, T2DM diagnosis was proved according to the American Diabetes Association practice guidelines. Their ages ranged from 35 to 83 years, with a mean of $54.69 \pm 8.855$ years, the median of ages was 55 years and Group 2: 106 healthy normal individuals undergoing a routine checkup at Ain Shams University hospitals. Their ages ranged from 36 to 69 years, with a mean age $53.29 \pm 7.04$ years, the median was 53 years. The age and sex are matched between the 2 groups.

Page 2/17 
Inclusion criteria of the study; Proved diagnosis of T2DM according to ADA practice guidelines, age of $>18$ years at the time of consent giving and the ability to provide a written, informed consent, Exclusion criteria of the study; History of malignant disease, patients on steroids for the last 6 months, end stage organ disease as chronic liver disease ,pregnant or lactating women.

Whole Blood samples were collected at Ain Shams University hospitals during the period March 2018 to May 2019. Sera were obtained by centrifugation while Peripheral Blood Mononuclear Cells (PBMCs) were isolated using lymphoprep (Axis-Shield PoC AS, Oslo, Norway). All participants signed an informed consent and the study was approved by the ethical committee of the Faculty of Medicine at ASU no. FWA 000017585.

Sera were obtained by centrifugation while Peripheral Blood Mononuclear Cells (PBMCs) were isolated using lymphoprep (Axis-Shield PoC AS, Oslo, Norway). All participants signed an informed consent and the study was approved by the ethical committee of the Faculty of Medicine at ASU no. FWA 000017585.

\section{2 | Measurement Of HOMA-IR:}

Fasting insulin level was measured in sera of diabetic patients and healthy controls using enzyme-linked immunosorbent assay ELISA (DRG ${ }^{8}$ Insulin ELISA (EIA-2935), DRG International, Inc. USA). Homeostatic Model Assessment of Insulin Resistance (HOMA-IR) was calculated according to the equation: Fasting insulin $(\mu \mathrm{U} / \mathrm{L}) \times$ fasting glucose $(\mathrm{nmol} / \mathrm{L}) / 22.5^{11}$

\section{3 | Bioinformatics-based selection of ceRNA panel related to insulin resistance:}

The identified panel was obtained through the following steps:

Retrieval of a set of candidate genes (mRNAs) related to insulin resistance signaling pathways from two public microarray databases available at (https://www.ebi.ac.uk/gxa/home) and (https://www.proteinatlas.org). Verification of the identified candidate genes expression in skeletal muscle and adipose tissues through gene cards (https://www.genecards.org/), so as to decrease the false discovery rate. Construction of mRNA/ miRNA/ IncRNA genetic axis linked to the identified candidate genes in IR in T2DM including LncRNA-RP11-773H22.4, miR-3163 and miR-1 microRNAs using a InCeDB database, available at (http://gyanxet-beta.com/Incedb/index.php). Alignment between LncRNA-RP11-773H22.4 and retrieved miRNAs: miR-3163 and miR-1, alignment between $m T O R$ mRNA and retrieved miRNAs, as well as, the alignment between LnCRNA-RP11-773H22.4 and the 2 synthesized gRNAs, to identify sequences of IncRNA-miRNAs interactions to be targeted by CRISPR/Cas9 gene editing tool through alignment database tool available at (https://www.ebi.ac.uk/gxa/home). Detailed bioinformatics are shown in supplementary figures (1a-o).

\section{4 | Validation of the identified ceRNA panel related to insulin resistance in human clinical samples:}

\subsubsection{Extraction of total RNA, including IncRNA, miRNAs, and mRNAs from human PBMCs samples.}

We used miRNeasy ${ }^{\circledR}$ RNA isolation kit (Cat no. 74104; Qiagen, USA) to extract total RNA from the PBMCs following the manufacturer's instructions. We assessed the RNA concentration and integrity using DeNovix DS-11 micro-volume spectrophotometer (Wilmington, USA). Then, it was reverse transcribed into cDNA using RT2 first strand kit (Cat no. 330401; Qiagen, USA) for the target mRNAs and miScript II RT Kit (Cat no. 218161; Qiagen, USA) for the non-coding RNAs as per the manufacturer's protocol using Thermo Hybaid PCR express (Thermo Scientific, USA).

\subsubsection{Quantitative real time-PCR of the identified ceRNA panel related to insulin resistance:}

The levels of the identified mRNAs (RET, IGF1-R, m-TOR, GLUT-4 and AKT2) in PBMCs were measured using custom RT ${ }^{2}$ Profiler" ${ }^{\text {TM }}$ PCR Array (Cat no. 330171 ; Qiagen, Helman Germany, Ensembl: ENSG00000165731, ENSG00000140443, ENSG00000198793, ENSG00000181856 and ENSG00000105221, respectively) and RT² SYBR Green ROX qPCR Mastermix (Cat no: 330520 ;Qiagen, Helman Germany), using Applied Biosystems Tm 7500 Real-Time PCR system (Foster city, California, United States). Relative expression levels for LncRNA-RP11-773H22.4 were analyzed by RT² SYBR Green ROX qPCR Master mix (Cat no: 330520; Qiagen, Helman Germany) and IncRNA qPCR Primer Assay for Human RP11-773H22.4 (ENST00000588211) supplied by Qiagen. GAPDH(Ensembl: ENSG00000111640) was used as a reference gene. miR-3163 and miR-1 miRNAs relative expression levels in PBMCs were investigated by a miScript SYBR Green PCR Kit (Cat no. 218073; Qiagen, Helman Germany), a miScript universal primer and a miRNA-specific forward primer (Hs_miR-3163_1 miScript Primer Assay) (Accession: MIMAT0015037) (Cat no. MS00020769; Qiagen, Helman Germany) for miR-3163 and (Hs_mir-1-1_PR_1 miScript Precursor Assay) (Accession: MI0000651) (Cat no. MP00000175; Qiagen, Helman Germany) for miR-1, and RNU-6 was used as an internal control. All PCR primers were obtained from Qiagen. The PCR program cycling conditions were adjusted according to the type of the measured RNA according to the manufacturer's protocol. The $2^{-\Delta \Delta C t}$ technique was used to measure the expression of the IR specific RNA-based candidate genes panel using Applied Biosystems 7500 software v2.3. Reference genes were used as an internal control to normalize the raw data of the samples and compare these results to a reference sample. In this study, appropriate standardization strategies were carried out to recognize any experimental error introduced at any stage during extraction and processing of the RNA according to MIQE guidelines ${ }^{12}$.

\section{5 | Validation of the identified ceRNA panel related to insulin resistance and CRISPR/CAS9 editing of LncRNA-RP11-773H22.4 in lymphocyte cell line:}

\subsubsection{Culture Of Human Lymphocytes}

Human cell culture was conducted as previously described ${ }^{13}$. The PBMCs were transferred in $20 \mathrm{~mL}$ RPMI 1640 media to a T-75 culture flask containing: $10 \%$ fetal bovine serum, $1 \%$ penicillin/streptomycin, $1 \mu \mathrm{g} / \mathrm{mL}$ phytohemagglutinin (PHA) and incubated at $37^{\circ} \mathrm{C}$ with $5 \% \mathrm{CO}_{2}$ for 24 hours. Next day, all the media was removed from the flask, and the cell pellet was added to a $50 \mathrm{~mL}$ conical tube and centrifuged at $500 \mathrm{Xg}$ for 5 minutes. The pellet which contained mainly lymphocytes was resuspended. The cells were transferred to a new T-75 culture flask in $25 \mathrm{~mL}$ RPMl 1640 media containing: 10\% fetal bovine serum, $1 \%$ penicillin/streptomycin, $1 \mu \mathrm{g} / \mathrm{mL}$ PHA and incubated at $37^{\circ} \mathrm{C}$ for 3 days. After 24 hours of growth, $20 \mathrm{~mL}$ of fresh media was added and transferred to a larger 
T-175 culture flask. After 3 days, media and suspended cells were removed from the culture flask and transferred to a $50 \mathrm{~mL}$ conical tube then centrifuged at $500 \mathrm{Xg}$ for 5 minutes. The pellet was resuspended and transferred to a new T-75 culture flask containing $25 \mathrm{~mL}$ RPMI 1640 with $10 \%$ fetal bovine serum, $1 \%$ penicillin/streptomycin. Lymphocytes were grown for 4 days.

\subsubsection{Synthesis Of Grnas}

DNA oligonucleotides used for gRNA synthesis were designed with the GeneArt ${ }^{\text {TM }}$ CRISPR gRNA Design Tool (available at: www.thermofisher.com). The two gRNAs were then synthesized using the GeneArt ${ }^{\text {TM }}$ Precision gRNA Synthesis Kit according to the manufacture's protocol and each was combined with GeneArt $^{\text {TM }}$ Platinum ${ }^{\text {TM }}$ Cas9 Nuclease to form the Cas9 protein/gRNA ribonucleoprotein complexes (Cas9 RNPs), Fig. 2s and table 1s.

\subsubsection{Lymphocyte transfection in a 12-well plate using Lipofectamine CRISPRMAX Reagent}

$50 \mu \mathrm{l}$ Opti-MEM medium was mixed with $1.25 \mu \mathrm{g}$ GeneArt Platinum Cas9 nuclease and $0.25 \mu \mathrm{g}$ gRNA, then vortexed with $2.5 \mu \mathrm{l}$ Cas 9 Plus and incubated at 25 for 5 min to form RNPs. $3 \mu$ l of Lipofectamine CRISPRMAX with 50 ul Opti-MEM were mixed and incubated at 25 for 5 min before being added to RNPs solution. The mixture was incubated at 25 for $15 \mathrm{~min}$, then added to cells that were plated onto 12 -well plates at a density of $8.5 \times 10^{5}$ cells/well in $1 \mathrm{ml}$ growth medium. $72 \mathrm{~h}$ post-transfection, lymphocytes were harvested for cell count and viability using trypan blue exclusion method and gene expression was analyzed before and after editing ${ }^{14}$. The genomic cleavage efficiency was measured by GeneArt® Genomic Cleavage Detection kit.

2.5.4 Immunofluorescence microscopy to evaluate the activity of GLUT-4 and m-TOR proteins as major effector target proteins in the molecular pathogenesis of IR in T2DM:

The harvested cells were examined by immunofluorescence staining with specific polyclonal antibodies against solute carrier family 2 member4 (SLC2A-4/ GLUT-4) (Cat.no.FNab03503, FineTest, Hubei, China). and mammalian target of rapamycin (m-TOR) protein (Cat.no. FNab05417, FineTest, Hubei, China) (green). An alexfluor 488 anti-rabbit IgG secondary antibody (Cat.no.A-11034, Invitrogen; ThermoFisher Scientific, Hilden; Germany) was used for detection. Fluorescence was examined by immunofluorescence microscope (Labmed; USA), using Optika ISview image acquisition and processing software.

\section{6 | Statistics}

Statistical Package for the Social Sciences (SPSS, Chicago, IL) version 20 was used to perform all statistical analyses. Kruskal-Wallis test, Mann-Whitney rank sum $U$ test, independent samples t-test, ANOVA and chi square test were used for comparison, as appropriate. (ROC) curves were used to explore the predictive value of investigated panel. The relationships between the investigated parameters were assessed using Spearman rank correlations. A 2-tailed $p$ value of $\leq$ 0.05 was considered a statistically significant.

\section{7 | Data And Resource Availability}

The datasets and RESOURCE generated during and/or analyzed during the current study are available from the corresponding author upon reasonable request.

\section{Results}

\subsection{Demographic, clinical data and diabetes laboratory profile of the diabetic and healthy groups}

Demographic data regarding age, sex and smoking showed no significant difference $(p>0.05)$. There were significant differences in fasting and 2 hour post prandial blood glucose level, BMI, blood pressure, lipid profile, albumin and creatinine ratio (alb./creat)., fasting insulin, glycosylated hemoglobin A1c (HbA1c), HOMA-IR between the diabetic and healthy groups $(p<0.05)($ Table 1$)$.

\section{Table (1)}

Study demographic data between the diabetic and healthy groups $(\mathrm{N}=229)$ 


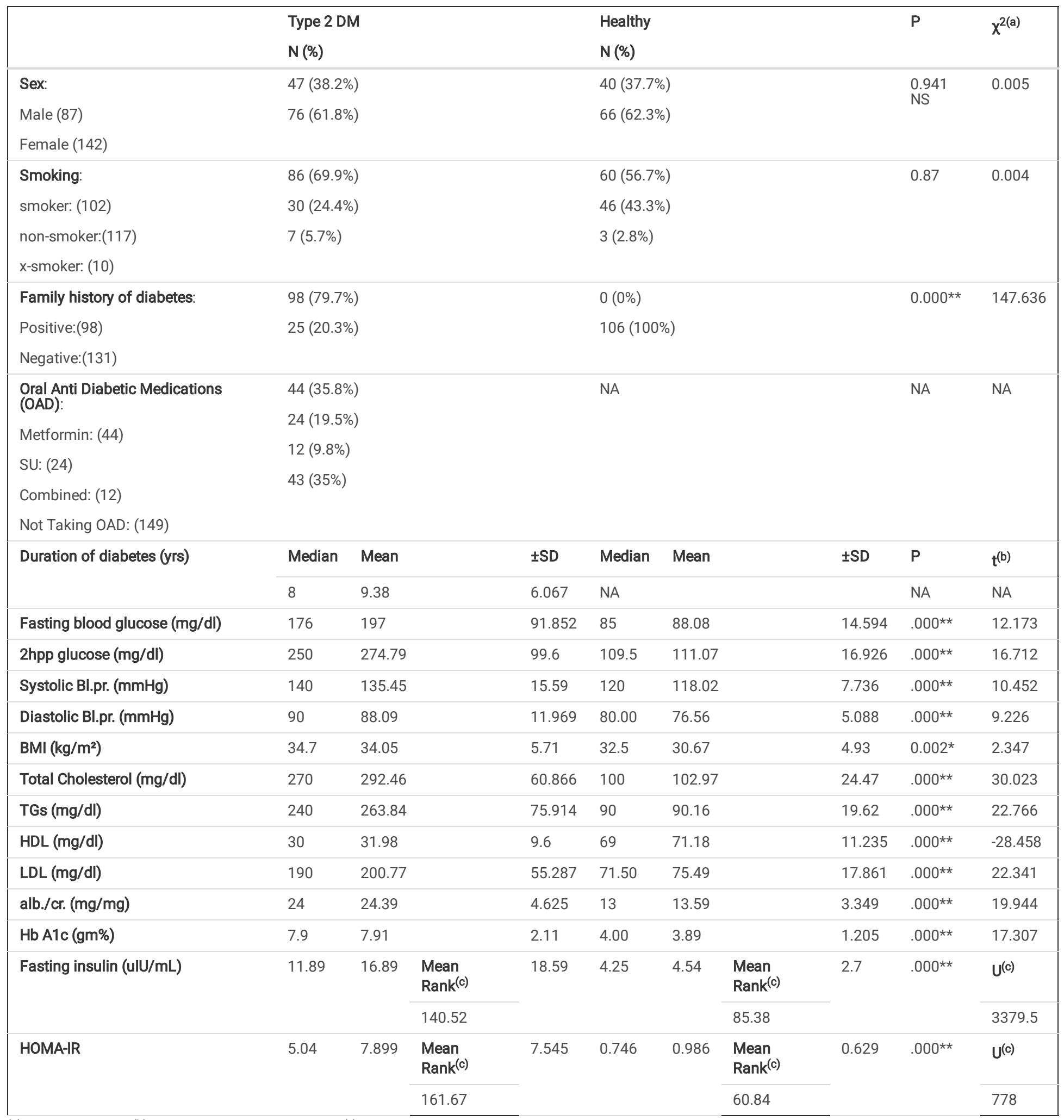

(a) Chi-Square test, ${ }^{(b)}$ Independent Samples T test, ${ }^{(c)}$ Mann-Whitney test, ${ }^{* * p}<0.01$ : is highly significant, FBG: Fasting Blood glucose, $2 \mathrm{hPP}$ BG: 2 hour postprandial blood glucose, BMI: Body Mass Index, HDL: high density lipoprotein, LDL: low density lipoprotein, TGs: Triglycerides, alb./cr.: albumin/creatinine ratio, HbA1c: Hemoglobin A1c, HOMA-IR: Homeostatic Model Assessment of Insulin Resistance.

\section{2 | Evaluation of the identified ceRNA panel expression in the diabetic and healthy groups}

In T2DM, LnCRNA-RP11-773H22.4, together with RET, IGF1-R and m-TOR mRNAs showed significant upregulation. On the other hand, the miRNAs: miR-3163, miR-1and mRNAs: GLUT-4 and AKT2 displayed marked downregulation compared to the control group (table 2 and Figs. 1a,b).

We calculated the sensitivity and specificity of each partner in the genetic network by ROC curve analyses (Fig. 2s). The overall positivity rates of these candidate genes in the diabetic and healthy groups are shown in table (2). 
Table (2)

Differential expression of RP11-773H22.4, miR-3163 and miR-1 miRNAs RET, IGF1-R, $m$-TOR, GLUT-4 and AKT2 mRNAs in the investigated groups ( $\mathrm{n}=229$ )

\begin{tabular}{|c|c|c|c|c|c|c|c|c|c|c|}
\hline & \multicolumn{8}{|l|}{ Group } & \multirow[t]{3}{*}{$\mathbf{P}$} & \multirow[t]{3}{*}{$U^{(a)}$} \\
\hline & \multicolumn{4}{|c|}{ Type 2DM } & \multicolumn{4}{|c|}{ Healthy normal } & & \\
\hline & Median & Mean & SD & Mean Rank & Median & Mean & SD & Mean rank & & \\
\hline RP11-773H22.4 IncRNA RQ & 5.09 & 14.34 & 18.86 & 164.93 & 1.00 & 1.03 & 0.09 & 57.07 & $.000 * *$ & 378 \\
\hline miR-3163 miRNA RQ & 0.117 & 0.59 & 2.02 & 72.84 & 1.04 & 1.14 & 0.241 & 163.92 & $.000 * \star$ & 1333 \\
\hline miR-1 miRNA RQ & 0.129 & 2.06 & 7.98 & 83.51 & 1.06 & 1.08 & 0.23 & 151.54 & $.000 * *$ & 2646 \\
\hline RET mRNA RQ & 37.55 & 63.94 & 79.23 & 161.71 & 1.00 & 1.04 & 0.143 & 60.80 & $.000 \star *$ & 774 \\
\hline IGF1-R mRNA RQ & 11.04 & 68.69 & 131.56 & 149.58 & 1.00 & 1.016 & 0.102 & 74.87 & $.000 * *$ & 2265.5 \\
\hline$m$-TOR mRNA RQ & 9.71 & 36.72 & 71.70 & 153.20 & 1.00 & 1.06 & 0.227 & 70.67 & $.000 \star \star$ & 1820 \\
\hline GLUT-4 mRNA RQ & 0.08 & 0.44 & 0.99 & 72.93 & 1.26 & 1.19 & 0.215 & 163.82 & $.000 \star *$ & 1344 \\
\hline AKT2 mRNA RQ & 0.433 & 0.501 & 0.424 & 68.05 & 1.22 & 1.20 & 0.186 & 169.48 & $.000 * *$ & 744.5 \\
\hline
\end{tabular}

\section{3 | Correlation between different partners in the genetic network, glycemic control, insulin resistance in both diabetic and healthy groups}

There was a highly significant positive correlation between each of the following: LnCRNA-RP11-773H22.4, RET, IGF1-R, $m$-TOR mRNAs, glycemic control and insulin resistance. Whereas, we observed a marked negative correlation between each of the abovementioned parameters and miR-3163, miR-1 miRNAs, GLUT4 and AKT2 mRNAs in both the diabetic and healthy groups $(\mathrm{P}<0.01)$ using Spearman's correlation as shown in table $(3)$.

\section{Table (3)}

Positivity rate of HOMA-IR and the investigated candidate genes in the investigated groups according to the calculated cutoff $(n=229)$ 


\begin{tabular}{|c|c|c|c|c|}
\hline & $\begin{array}{l}\text { Type 2DM } \\
\mathrm{N}(\%)\end{array}$ & $\begin{array}{l}\text { Healthy } \\
\mathrm{N}(\%)\end{array}$ & $\mathbf{P}$ & $\chi^{2(a)}$ \\
\hline HOMA-IR & $102(82.9 \%)$ & $0(0 \%)$ & $.000 \star \star$ & 158.501 \\
\hline Positive $\geq 2.3$ (102) & $21(17.1 \%)$ & $106(100 \%)$ & & \\
\hline \multicolumn{5}{|l|}{ Negative < 2.3 (127) } \\
\hline LncRNA-RP11-773H22.4 RQ: & 117 (95.1\%) & $7(6.6 \%)$ & $.000 * \star$ & 179.680 \\
\hline Positive $\geq 1.2$ (124) & $6(4.9 \%)$ & $99(93.4 \%)$ & & \\
\hline \multicolumn{5}{|l|}{ Negative < $1.2(105)$} \\
\hline miR-3163 RQ: & $109(88.6 \%)$ & $11(10.4 \%)$ & $.000 * *$ & 139.734 \\
\hline Positive $\leq 0.91$ (120) & $14(11.4 \%)$ & $95(89.6 \%)$ & & \\
\hline \multicolumn{5}{|l|}{ Negative >0.91 (109) } \\
\hline miR-1 RQ: & $96(78 \%)$ & $20(18.9 \%)$ & $.000 * *$ & 79.776 \\
\hline Positive $\leq 0.87$ (116) & $27(22 \%)$ & $86(81.1 \%)$ & & \\
\hline \multicolumn{5}{|l|}{ Negative $>0.87(113)$} \\
\hline RET mRNA RQ: & $114(92.7 \%)$ & $3(2.8 \%)$ & $.000 \star \star$ & 183.952 \\
\hline Positive $\geq 1.36$ (117) & $9(7.3 \%)$ & $103(97.2 \%)$ & & \\
\hline \multicolumn{5}{|l|}{ Negative < 1.36 (112) } \\
\hline m-TOR mRNA RQ: & $105(85.4 \%)$ & $11(10.4 \%)$ & $.000 * \star$ & 128.085 \\
\hline Positive $\geq 1.4$ (116) & $18(14.6 \%)$ & $95(89.6 \%)$ & & \\
\hline \multicolumn{5}{|l|}{ Negative < $1.4(113)$} \\
\hline IGF1-R mRNA RQ: & $98(79.7 \%)$ & $2(1.9 \%)$ & $.000 \star \star$ & 140.050 \\
\hline Positive $\geq 1.07$ (100) & $25(20.3 \%)$ & $104(98.1 \%)$ & & \\
\hline \multicolumn{5}{|l|}{ Negative < 1.07 (129) } \\
\hline GLUT-4 mRNA RQ: & 109 (88.6\%) & $7(6.6 \%)$ & $.000 \star \star$ & 153.210 \\
\hline Positive $\leq 0.92(116)$ & $14(11.4 \%)$ & $99(93.4 \%)$ & & \\
\hline \multicolumn{5}{|l|}{ Negative > $0.92(113)$} \\
\hline AKT2 mRNA RQ: & 113(91.9\%) & $5(4.7 \%)$ & $.000 * \star$ & 173.143 \\
\hline Positive $\leq 0.99$ (118) & $10(8.1 \%)$ & $101(95.3 \%)$ & & \\
\hline \multicolumn{5}{|l|}{ Negative $>0.99(111)$} \\
\hline
\end{tabular}

\subsection{CRISPR/Cas9 mediated knockout of LncRNA-RP11-773H22.4 in lymphocyte cell line obtained from diabetic patients}

\subsubsection{Effect of CRISPR/Cas9 editing on cell count and viability}

By applying one-way ANOVA post hoc test, we could not observe any difference in lymphocyte's count and viability in the diabetic cell line before and after CRISPR/Cas9 editing. Of note, CRISPR editing slightly decreased the cell count and viability as compared to healthy control which may be because of its potential genotoxic effect or its companion chemicals used for its transfection for further study (Table 2s).

\subsubsection{Effect of CRISPR/Cas9 editing on the expression of the identified genetic network.}

CRISPR/Cas9 gene editing, modify the gene expression of the identified network, whereas the expression of LncRNA-RP11-773H22.4, RET, IGF1-R and $m$-TOR mRNAs were significantly decreased $(\mathrm{P}<0.01)$, while miR-3163, miR-1, GLUT-4 and AKT2 mRNAs were obviously increased after CRISPR/Cas 9 knockout of LncRNA-RP11-773H22.4 ( $\mathrm{P}<0.01)$ as shown in table (4).

\section{Table (4)}

Differential expression of LnCRNA-RP11-773H22.4, miR-3163 and miR-1 miRNAs RET, IGF1-R, m-TOR, GLUT-4 and AKT2 mRNAs between lymphocytes' cell lines before and after CRISPR/Cas9 editing 


\begin{tabular}{|c|c|c|c|c|c|c|}
\hline & \multicolumn{4}{|c|}{ Lymphocytes' cell lines } & \multirow[t]{3}{*}{$\mathbf{P}$} & \multirow[t]{3}{*}{$\mathrm{U}^{2(\mathrm{a})}$} \\
\hline & \multicolumn{2}{|c|}{ T2DM lymphocytes without editing } & \multicolumn{2}{|c|}{ T2DM lymphocytes with CRISPR editing } & & \\
\hline & Median & Mean Rank & Median & Mean Rank & & \\
\hline LncRNA-RP11-773H22.4 RQ & 5.8 & 14 & 0.399 & 5 & $.000 * \star$ & .000 \\
\hline miR-3163 miRNA RQ & 0.139 & 5 & 88.13 & 14 & $.001 * \star$ & .000 \\
\hline miR-1 miRNA RQ & 0.181 & 5 & 533.577 & 14 & .001 ** & .000 \\
\hline RET $m R N A \mathrm{RQ}$ & 110.98 & 14 & 0.137 & 5 & $.000 * *$ & .000 \\
\hline IGF1-R mRNA RQ & 29.75 & 14 & 0.177 & 5 & $.000 * *$ & .000 \\
\hline$m$-TOR mRNA RQ & 11.86 & 14 & 0.331 & 5 & $.000 * *$ & .000 \\
\hline GLUT-4 mRNA RQ & 0.343 & 5 & 2.217 & 14 & $.000^{* *}$ & .000 \\
\hline AKT2 mRNA RQ & 0.027 & 5 & 48.83 & 14 & $.000 * *$ & .000 \\
\hline
\end{tabular}

There was a marked positive correlation between each of the following: LnCRNA-RP11-773H22.4, RET, IGF1-R, $m$-TOR mRNAs. However, we noticed a highly significant negative correlation between each of the above mentioned parameters and miR-3163, miR-1 miRNAs, GLUT-4 and AKT2 mRNAs among the diabetic groups before and after CRISPR/Cas9 editing and the control group $(\mathrm{P}<0.01)$ using Spearman's correlation (Tables 5 and 6$)$.

\section{Table (5)}

Correlation between the investigated parameters expression in both the diabetic and healthy groups $(n=229)$ 


\begin{tabular}{|c|c|c|c|c|c|c|c|c|c|c|}
\hline & & IncRNA_RQ & miR_3163_RQ & miR_1RQ & RET_RQ & IGF1R_RQ & mTOR_RQ & GLUT4_RQ & AKT2_RQ & $\mathrm{HbA1c}$ \\
\hline \multirow[t]{3}{*}{ IncRNA_RQ } & $\begin{array}{l}\text { Correlation } \\
\text { Coefficient }\end{array}$ & 1.000 & -.515 & -.366 & .656 & .483 & .469 & -.579 & -.588 & .651 \\
\hline & $\begin{array}{l}\text { Sig. (2- } \\
\text { tailed) }\end{array}$ & . & .000 & .000 & .000 & .000 & .000 & .000 & .000 & .000 \\
\hline & $\mathrm{N}$ & 229 & 229 & 229 & 229 & 229 & 229 & 229 & 229 & 229 \\
\hline \multirow[t]{3}{*}{ miR_3163_RQ } & $\begin{array}{l}\text { Correlation } \\
\text { Coefficient }\end{array}$ & -.515 & 1.000 & .459 & -.475 & -.330 & -.399 & .455 & .505 & -.576 \\
\hline & $\begin{array}{l}\text { Sig. (2- } \\
\text { tailed) }\end{array}$ & .000 & . & .000 & .000 & .000 & .000 & .000 & .000 & .000 \\
\hline & $\mathrm{N}$ & 229 & 229 & 229 & 229 & 229 & 229 & 229 & 229 & 229 \\
\hline \multirow[t]{3}{*}{ miR_1RQ } & $\begin{array}{l}\text { Correlation } \\
\text { Coefficient }\end{array}$ & -.366 & .459 & 1.000 & -.457 & -.290 & -.259 & .377 & .412 & -.362 \\
\hline & $\begin{array}{l}\text { Sig. (2- } \\
\text { tailed) }\end{array}$ & .000 & .000 & . & .000 & .000 & .000 & .000 & .000 & .000 \\
\hline & $\mathrm{N}$ & 229 & 229 & 229 & 229 & 229 & 229 & 229 & 229 & 229 \\
\hline \multirow[t]{3}{*}{ RET_RQ } & $\begin{array}{l}\text { Correlation } \\
\text { Coefficient }\end{array}$ & .656 & -.475 & -.457 & 1.000 & .694 & .440 & -.491 & -.615 & .562 \\
\hline & $\begin{array}{l}\text { Sig. (2- } \\
\text { tailed) }\end{array}$ & .000 & .000 & .000 & . & .000 & .000 & .000 & .000 & .000 \\
\hline & $\mathrm{N}$ & 229 & 229 & 229 & 229 & 229 & 229 & 229 & 229 & 229 \\
\hline \multirow[t]{3}{*}{ IGF1R_RQ } & $\begin{array}{l}\text { Correlation } \\
\text { Coefficient }\end{array}$ & .483 & -.330 & -.290 & .694 & 1.000 & .392 & -.362 & -.420 & .462 \\
\hline & $\begin{array}{l}\text { Sig. (2- } \\
\text { tailed) }\end{array}$ & .000 & .000 & .000 & .000 & . & .000 & .000 & .000 & .000 \\
\hline & $\mathrm{N}$ & 229 & 229 & 229 & 229 & 229 & 229 & 229 & 229 & 229 \\
\hline \multirow[t]{3}{*}{ mTOR_RQ } & $\begin{array}{l}\text { Correlation } \\
\text { Coefficient }\end{array}$ & .469 & -.399 & -.259 & .440 & .392 & 1.000 & -.421 & -.488 & .547 \\
\hline & $\begin{array}{l}\text { Sig. (2- } \\
\text { tailed) }\end{array}$ & .000 & .000 & .000 & .000 & .000 & . & .000 & .000 & .000 \\
\hline & $\mathrm{N}$ & 229 & 229 & 229 & 229 & 229 & 229 & 229 & 229 & 229 \\
\hline \multirow[t]{3}{*}{ GLUT4_RQ } & $\begin{array}{l}\text { Correlation } \\
\text { Coefficient }\end{array}$ & -.579 & .455 & .377 & -.491 & -.362 & -.421 & 1.000 & .523 & -.517 \\
\hline & $\begin{array}{l}\text { Sig. (2- } \\
\text { tailed) }\end{array}$ & .000 & .000 & .000 & .000 & .000 & .000 & . & .000 & .000 \\
\hline & $\mathrm{N}$ & 229 & 229 & 229 & 229 & 229 & 229 & 229 & 229 & 229 \\
\hline \multirow[t]{3}{*}{ AKT2_RQ } & $\begin{array}{l}\text { Correlation } \\
\text { Coefficient }\end{array}$ & -.588 & .505 & .412 & -.615 & -.420 & -.488 & .523 & 1.000 & -.614 \\
\hline & $\begin{array}{l}\text { Sig. (2- } \\
\text { tailed) }\end{array}$ & .000 & .000 & .000 & .000 & .000 & .000 & .000 & . & .000 \\
\hline & $\mathrm{N}$ & 229 & 229 & 229 & 229 & 229 & 229 & 229 & 229 & 229 \\
\hline \multirow[t]{3}{*}{$\mathrm{HbA} 1 \mathrm{c}$} & $\begin{array}{l}\text { Correlation } \\
\text { Coefficient }\end{array}$ & .651 & -.576 & -.362 & .562 & .462 & .547 & -.517 & -.614 & 1.000 \\
\hline & $\begin{array}{l}\text { Sig. (2- } \\
\text { tailed) }\end{array}$ & .000 & .000 & .000 & .000 & .000 & .000 & .000 & .000 & . \\
\hline & $N$ & 229 & 229 & 229 & 229 & 229 & 229 & 229 & 229 & 229 \\
\hline \multirow[t]{3}{*}{ HOMA_IR } & $\begin{array}{l}\text { Correlation } \\
\text { Coefficient }\end{array}$ & .581 & -.555 & -.378 & .543 & .296 & .415 & -.573 & -.608 & .611 \\
\hline & $\begin{array}{l}\text { Sig. (2- } \\
\text { tailed) }\end{array}$ & .000 & .000 & .000 & .000 & .000 & .000 & .000 & .000 & .000 \\
\hline & $\mathrm{N}$ & 229 & 229 & 229 & 229 & 229 & 229 & 229 & 229 & 229 \\
\hline
\end{tabular}

*Spearman's Correlation: NS, Not significant $(>0.05),{ }^{* \star} p<0.01$ : is highly significant, ${ }^{\star} p<0.05$ : is significant. HbA1c: Hemoglobin A1c, HOMA-IR: Homeostatic Assessment of Insulin Resistance. 
Table (6)

Correlation between the investigated candidate genes expression in the 3 investigated lymphocytes' cell lines

\begin{tabular}{|c|c|c|c|c|c|c|c|c|c|}
\hline \multicolumn{2}{|l|}{ Correlations } & \multirow[b]{2}{*}{ IncRNA_RQ } & \multirow[b]{2}{*}{ miR_3163_RQ } & \multirow[b]{2}{*}{$\begin{array}{l}\text { miR_1 } \\
\text { RQ }\end{array}$} & \multirow[b]{2}{*}{$\begin{array}{l}\text { RET_- } \\
\text { RQ }\end{array}$} & \multirow[b]{2}{*}{$\begin{array}{l}\text { IGF1R_ } \\
\mathrm{RQ}\end{array}$} & \multirow[b]{2}{*}{ mTOR_RQ } & \multirow[b]{2}{*}{ GLUT_4RQ } & \multirow[b]{2}{*}{ AKT2_RQ } \\
\hline & & & & & & & & & \\
\hline \multirow[t]{3}{*}{ IncRNA_RQ } & $\begin{array}{l}\text { Correlation } \\
\text { Coefficient }\end{array}$ & 1.000 & $-.931^{\star \star}$ & $-.983^{\star *}$ & $.914^{\star *}$ & $.931^{\star *}$ & $.879^{* *}$ & $-.897^{\star \star}$ & $-.879^{\star \star}$ \\
\hline & Sig. (2-tailed) & . & .000 & .000 & .000 & .000 & .000 & .000 & .000 \\
\hline & $\mathrm{N}$ & 27 & 27 & 27 & 27 & 27 & 27 & 27 & 27 \\
\hline \multirow[t]{3}{*}{ miR_3163_RQ } & $\begin{array}{l}\text { Correlation } \\
\text { Coefficient }\end{array}$ & $-.931^{\star \star}$ & 1.000 & $.965^{* *}$ & $-.948^{\star \star}$ & $-.965^{\star \star}$ & $-.931^{\star \star}$ & $.913^{\star \star}$ & $.948^{\star \star}$ \\
\hline & Sig. (2-tailed) & .000 & . & .000 & .000 & .000 & .000 & .000 & .000 \\
\hline & $\mathrm{N}$ & 27 & 27 & 27 & 27 & 27 & 27 & 27 & 27 \\
\hline \multirow[t]{3}{*}{ miR_1RQ } & $\begin{array}{l}\text { Correlation } \\
\text { Coefficient }\end{array}$ & $-.983^{\star \star}$ & $.965^{\star *}$ & 1.000 & $-.931^{\star \star}$ & $-.948^{\star \star}$ & $-.897^{\star \star}$ & $.879^{\star \star}$ & $.897^{\star *}$ \\
\hline & Sig. (2-tailed) & .000 & .000 & . & .000 & .000 & .000 & .000 & .000 \\
\hline & $\mathrm{N}$ & 27 & 27 & 27 & 27 & 27 & 27 & 27 & 27 \\
\hline \multirow[t]{3}{*}{ RET_RQ } & $\begin{array}{l}\text { Correlation } \\
\text { Coefficient }\end{array}$ & $.914^{\star *}$ & $-.948^{\star \star}$ & $-.931^{\star \star}$ & 1.000 & $.983^{\star *}$ & $.983^{* *}$ & $-.914^{\star \star}$ & $-.931^{\star \star}$ \\
\hline & Sig. (2-tailed) & .000 & .000 & .000 & . & .000 & .000 & .000 & .000 \\
\hline & $\mathrm{N}$ & 27 & 27 & 27 & 27 & 27 & 27 & 27 & 27 \\
\hline \multirow[t]{3}{*}{ IGF1R_RQ } & $\begin{array}{l}\text { Correlation } \\
\text { Coefficient }\end{array}$ & $.931^{* *}$ & $-.965^{\star \star}$ & $-.948^{\star *}$ & $.983^{\star *}$ & 1.000 & $.948^{\star *}$ & $-.931^{\star \star}$ & $-.948^{\star *}$ \\
\hline & Sig. (2-tailed) & .000 & .000 & .000 & .000 & . & .000 & .000 & .000 \\
\hline & $\mathrm{N}$ & 27 & 27 & 27 & 27 & 27 & 27 & 27 & 27 \\
\hline \multirow[t]{3}{*}{ mTOR_RQ } & $\begin{array}{l}\text { Correlation } \\
\text { Coefficient }\end{array}$ & $.879^{\star \star}$ & $-.931^{\star \star}$ & $-.897^{\star \star}$ & $.983^{\star \star}$ & $.948^{\star *}$ & 1.000 & $-.931^{\star \star}$ & $-.948^{\star \star}$ \\
\hline & Sig. (2-tailed) & .000 & .000 & .000 & .000 & .000 & . & .000 & .000 \\
\hline & $\mathrm{N}$ & 27 & 27 & 27 & 27 & 27 & 27 & 27 & 27 \\
\hline \multirow[t]{3}{*}{ GLUT_4RQ } & $\begin{array}{l}\text { Correlation } \\
\text { Coefficient }\end{array}$ & $-.897^{\star \star}$ & $.913^{\star *}$ & $.879^{\star *}$ & $-.914^{\star \star}$ & $-.931^{\star \star}$ & $-.931^{\star \star}$ & 1.000 & $.983^{\star \star}$ \\
\hline & Sig. (2-tailed) & .000 & .000 & .000 & .000 & .000 & .000 & . & .000 \\
\hline & $\mathrm{N}$ & 27 & 27 & 27 & 27 & 27 & 27 & 27 & 27 \\
\hline \multirow[t]{3}{*}{ AKT2_RQ } & $\begin{array}{l}\text { Correlation } \\
\text { Coefficient }\end{array}$ & $-.879^{\star \star}$ & $.948^{\star *}$ & $.897^{\star *}$ & $-.931^{\star *}$ & $-.948^{\star \star}$ & $-.948^{\star \star}$ & $.983^{\star \star}$ & 1.000 \\
\hline & Sig. (2-tailed) & .000 & .000 & .000 & .000 & .000 & .000 & .000 & . \\
\hline & $\mathrm{N}$ & 27 & 27 & 27 & 27 & 27 & 27 & 27 & 27 \\
\hline
\end{tabular}

*Spearman's Correlation: NS, Not significant $(>0.05)$, ${ }^{\star \star} p<0.01$ : is highly significant, ${ }^{*} p<0.05$ : is significant.

3.4.3 Effect of CRISPR/Cas9 editing on GLUT-4 and m-TOR proteins (major effectors in the insulin signaling pathway).

Lymphocytes obtained from healthy donors "normal pool" showed compact lymphocytes colonies with GLUT4 high fluorescence intensity and loss of mTOR expression (Figs. 2a,b). On the other hand, lymphocytes obtained from T2DM showed a merged collection "small colonies" of cells which were uniformly distributed of enlarged size, high nuclear/cytoplasmic ratio, irregular nuclear contour, with membrane vesicles and marked mTOR fluorescence intensity (+++) in cytoplasm and nucleus along with faint GLUT4 expression (+). After CRISPR editing, a discrete spread out lymphocytes were uniformly distributed of medium cell size, slightly regular nuclei, moderate nuclear /cytoplasmic ratio, and few membranous vesiculation with moderate faint fluorescence of mTOR $(+)$ and dense clustering expression of GLUT-4 with high fluorescence intensity (+++).

\section{Discussion}


Type 2 Diabetes is the commonest form of diabetes accounting for almost $90 \%$ of all cases with this debilitating illness. Characteristically, T2DM is defined by both insulin resistance and pancreatic beta cell malfunction, leading to hyperglycemia ${ }^{15}$.

In this study, we first constructed a competing endogenous RNA network and identified thereby, several potential key molecules. We described the important role played by non-coding RNAs in the pathogenesis of IR. Our study highlighted specific IncRNA, miRNAs and mRNAs related to the pathogenesis of IR and obtained from public databases, which might be used as novel therapeutic targets for type T2DM. Secondly, we evaluated the expression of this identified genetic network in clinical samples. Finally, we evaluated the therapeutic efficacy of the gene editing tool CRISPR/Cas9 in the improvement of IR in type 2DM in lymphocyte cell line.

Our results demonstrated that there was significant up-regulation in the expression of LnCRNA-RP11-773H22.4, RET, $m$-TOR and IGF1-R mRNAs, together with significant down-regulation in the expression of miR-3163, miR-1, GLUT-4 and AKT2 mRNAs in the diabetic group compared to the healthy control in both patients' clinical samples and lymphocyte cell line.

RET is a protooncogene residing on chromosome $10 q 11.2$ coding for a tyrosine kinase receptor.it participates in many intracellular signaling pathways including the PI3K-AKT and MAPK-ERK. The involvement of RET oncogene in the same pathway of insulin signaling may contribute to its link with the molecular pathogenesis of insulin resistance. Mutational activation of RET protooncogene results in the overproliferation of the affected cells as well as increased risk of metastasis and poor clinical outcome ${ }^{16}$. Consequently, RET mutation has been associated with multiple endocrine neoplasia ${ }^{17}$, medullary thyroid carcinoma ${ }^{18}$, breast cancer ${ }^{19}$, Non-Small Cell Lung Cancer (NSCLC) ${ }^{20}$, and many other malignancies. However, it has never been described in T2DM.

Glucose transporters (GLUTs), are a group of plasma membrane transporters that help glucose translocation into mammalian cells. The most noteworthy of these GLUTs is the glucose transporter 4 (GLUT 4), the center of most studies of insulin resistance since it is the major mean of glucose transport in insulinsensitive peripheral tissues i.e. skeletal muscles and adipose tissues. GLUT4, coded by SLC2A4 gene, transports glucose by a process of alternating between the plasma membrane and intracellular storage vesicles ${ }^{21}$. Surprisingly, GLUT4 has proven to be involved in cancer metastasis, through its role in cellular consumption of glucose at basal levels, cancer cell proliferation and survival in breast cancer cells ${ }^{22}$ and multiple myeloma cells ${ }^{23}$.

AKT-2 is an important mediator in the PI3K pathway involved in insulin signaling and influencing numerous downstream proteins that affect metabolism, growth, and cell survival. Akt2 expression is highest in insulin-sensitive tissues and is believed to contribute largely to the role of insulin in metabolism ${ }^{24}$. Therefore, derangement in its protein product may contribute to the pathogenesis of insulin resistance and/or T2DM. Multiple studies have specified that Akt2 is responsible for insulin-dependent glucose uptake in humans as well as in rodents and its dysfunctional is related to insulin resistance and impaired glucose tolerance which goes hand in hand with our study ${ }^{25}$. AKT-2 amplification has been evident in one quarter of the cell lines of ovarian carcinoma and 2 out of 15 primary tumors of the ovary ${ }^{26}$. Furthermore, it has been implicated in other types of cancer, namely hepatocellular carcinoma ${ }^{27}$, breast and prostatic cancers ${ }^{28}$.The role of this gene is not exclusive to diabetes and cancer, it has also been shown to contribute to a lot of neurological and cardiovascular diseases $^{29}$.

The role of miRNAs has been delineated in several studies related to various critical protein cascades that share in insulin signaling pathways ${ }^{30}$. Among the most notable of these miRNAs is micro-RNA-1, described in several diseases and cancers. micro-RNA-1 is highly expressed in muscle cells where it suppresses proliferation of precursor cells and encourages myogenesis ${ }^{31}$. miR-1 downregulation shown to be related to diabetes induced oxidative stress. A study by Chen et al., revealed that under oxidative stress insulin regulates the function of miR-1 through AKT activation in H9c2 cells ${ }^{32}$. These results are similar to our study results that revealed the deregulation of miR-1 level in case of T2DM. Levels of circulating miR-1 have been associated with occurrence of myocardial infarction ${ }^{33}$. Also, it has been reported to suppress the growth of hepatocellular carcinoma cells by modulating ET-1 ${ }^{34}$ and to be down-regulated in primary human lung cancers ${ }^{35}$, gastric ${ }^{36}$ and breast cancers ${ }^{37}$.

In this study, the newly investigated miRNA: miR-3163 in T2DM is retrieved from databases based on its association with many downstream effectors in insulin signaling pathway. It was found that its level is significantly deregulated in T2DM in both clinical and cell line samples. In cancer, miR-3163 has been shown to have a role in suppressing the translation of Skp2 mRNA in NSCLC cells; hence, inhibiting their growth ${ }^{38}$. Furthermore, miRNA-363 strongly influences ACG2 expression affecting cell growth, apoptosis and resistance to drugs in retinoblastoma neoplastic stem cells ${ }^{39}$. It also has been shown to suppress tumorigenesis in ovarian cancer ${ }^{40}$.

In addition, recent studies reported that IncRNAs may work as competing endogenous RNAs (ceRNAs) and crosstalk with mRNAs by competitively bind their common pool of miRNAs in most of human diseases ${ }^{41}$.

Interestingly, our study demonstrated that $L n c-R N A-R P 11-773 H 22.4$ is expressed in patients with T2DM and it was correlated with poor glycemic control and insulin resistance, thus could then be used as a target of novel therapy These non-coding RNAs have been proven to be involved in many nodes in the development of cancer and DM through affecting the expression of the disease associated genes at the epigenetic level, as well as transcriptional and posttranscriptional levels ${ }^{8,42}$.

Insulin-like growth factor-1 receptor (IGF-1R) is a tyrosine kinase receptor that is critical for insulin signaling. It is now considered a key player in the activation of the phosphatidylinositol 3-kinase-AKT. The IGF-1R is considered to be one of the important receptor proteins for insulin signaling pathway. Specifically, IGF-1 and its receptor affect the sensitivity of muscle to insulin. Interestingly, Chakraborty et al., found that miR-1 influences the expression of both, IGF-1 and its receptor ${ }^{43}$. Through modulating IGF-1 and IGF-1R, miR-320 promotes insulin resistance in the endothelium and adipocytes. Moreover, it was previously established to be involved in malignant transformation of cells and neoplasia ${ }^{44}$ and implicated in breast ${ }^{45}$, colon $^{46}$ and prostate cancers ${ }^{47}$. Taken all together, we can conclude that the importance of IGF-1 and IGF-1R in insulin signaling and tumorigenesis is similar. More recent studies have demonstrated

Page $11 / 17$ 
that cross talk between insulin resistance and IGF-1R may also occur in malignancies, as increased insulin signaling is observed during the downregulation of IGF-1R in tumor cells ${ }^{48}$.

A key player in the phosphatidylinositol 3-kinase (PI3K)-related kinase family is mTOR, a special type of multi-subunit serine/threonine kinase. Surprisingly, mTOR is the target of the valuable drug rapamycin, which is used to coat coronary stents and prevent organ transplant rejection. This versatility can thus be explained by the critical role of mTOR in response to miscellaneous signaling cascades when stimulated by variations intracellular and environmental conditions ${ }^{49}$. Being a major node in the (PI3K/AKT/mTOR) pathway, we think that its disruption will result in hyperglycemia and diabetes ${ }^{50}$. mTOR activation influences multiple diseases such as cancer ${ }^{51}$, obesity ${ }^{52}$, cardiovascular diseases ${ }^{53}$ and neurodegenerative disorders ${ }^{54}$. Normal cells convey a special network interaction between all the aforementioned pathways. In our study there was a highly significant positive correlation between the expressions of LnCRNA-RP11-773H22.4, RET, m-TOR mRNAs, HbA1c and HOMA-IR. We observed a markedly negative correlation as well between them and miR-3163, miR-1 miRNAs expression in the diabetic and healthy groups $(\mathrm{P}<0.01)$. These correlations have been validated in both clinical samples and in lymphocyte cell line which concede with the in-silico data analysis. We believe that LncRNA-RP11-773H22.4 has an inhibitory effect on miR-3163 miRNA, thus releasing the inhibitory effect of that miRNA on RET MRNA and other mRNAs in the panel.

Our study provides evidence that CRISPR/Cas9 genome editing system is a simple, cheap, and fast tool to manipulate genomes which is expected to have a broader therapeutic application in insulin resistance by modulating the deregulated genetic network of insulin signaling pathway (Fig. 3).

figure (3): Proof of concept of ceRNA hypothesis in IR in T2DM

In this paper, we used for the first time an integrative approach based on computational method together with clinical validation to provide novel insights into the molecular mechanisms of IR. We implemented combined bioinformatics analysis to retrieve a set of ceRNA network (RET mRNA, LncRNA-RP11-773H22.4 and miRNA-3163 miRNA) related to insulin resistance and their targeting signaling pathway genes (IGF1-R, GLUT-4, AKT2 and $m$-TOR mRNAs) and (miR-1 miRNA), retrieved from public databases. Afterwards, we investigated the identified ceRNA network expression in patients' clinical samples and lymphocyte cell line by qPCR and IF. Then, we did CRISPR/Cas9 knockout of LncRNA-RP11-773H22.4 at the sequence of IncRNA-miRNA interaction in the cultured lymphocytes by designing more than one gRNA flanking the area of interaction. This approach resulted in the restoration of normal expression of the identified genes in comparison to the healthy controls as confirmed by qPCR and IF. We thereby, suggest the CRISPR/Cas9 knockout of LncRNA-RP11$773 \mathrm{H} 22.4$ as a potential therapeutic target for treatment of T2DM.

Taken together, our study offers valuable insights that help to decipher our understanding of diabetes and insulin resistance.

More invitro functional studies are needed to validate our result and consider the safety issues related to CRISPR/Cas 9 system; as genotoxicity and off target mutations with possibility of using more accurate nucleases to reduce off-target effects.

\section{Abbreviations}

T2DM: type 2 diabetes mellitus, ceRNA: competing endogenous RNA, LncRNA: long non-coding RNA, miRNA: microRNA, CRISPER: Clustered Regularly Interspaced Short Palindromic Repeats. Cas 9: Crisper associated protein 9, HOMA-IR: homeostatic model assessment of insulin resistance

\section{Declarations}

\section{*Ethics approval and consent to participate.}

The study was approved by the ASU-Faculty of Medicine ethical committee. All methods were carried out in accordance with declaration of Helsinki guidelines and regulations. Informed consent was obtained from all participants and/or their legal guardians.

\section{*Consent for publication.}

All authors have read the manuscript and agree to all its contents. All authors give their consent for publication.

\section{*Availability of data and materials.}

The datasets generated during and/or analysed during the current study are available from the corresponding author on reasonable request.

\section{*Competing interests.}

The authors declare no competing interests

\section{*Funding.}

The work was funded by Egyptian Academy of Scientific Research and Technology, JESOR grant ID: 2017-2961

\section{*Author Contributions}


M.M. and M.M.K: performed bioinformatics analysis, practical work, shared in the design of the study, statistical analysis and drafting the manuscript. G.F.M: shared in the cell culture and immunofluorescence experiments. S.E.: Shared in the design of the study, data analysis, drafting and revising the manuscript, and has given final approval of the version to be published. N.E and B.A: shared in drafting and revising the manuscript. M.M.B: shared by clinical evaluation of patient and clinical data collection.

\section{References}

1. Wu, Y., Ding, Y., Tanaka, Y. \& Zhang W. Risk factors contributing to type 2 diabetes and recent advances in the treatment and prevention. Int J Med Sci.11, 1185-200 (2014)

2. The IDF Diabetes Atlas Ninth edition (2019)

3. Hegazi, R., El-Gamal, M., Abdel-Hady, N. \& Hamdy, O. Epidemiology of and Risk Factors for Type 2 Diabetes in Egypt. Annals of Global Health. 81(6), 814 (2016)

4. Sommese L. et al. Clinical relevance of epigenetics in the onset and management of type 2 diabetes mellitus. Epigenetics.12(6),401-415 (2017)

5. Di Meo, S, lossa, S. \& Venditti, P. Skeletal muscle insulin resistance: role of mitochondria and other ROS sources. J Endocrinol.233(1), R15-R42 (2017)

6. Lin Z, et al. Construction of competitive endogenous RNA network reveals regulatory role of long non-coding RNAs in type 2 diabetes mellitus. $J$ Cell Mol Med. 12, 3204-3213 (2017)

7. Ulitsky I. Evolution to the rescue: using comparative genomics to understand long non-coding rnas. Nat Rev Genet.17, 601-614 (2016)

8. Sathishkumar, C., Prabu, P., Mohan, V., \& Balasubramanyam, M. Linking a role of IncRNAs (long non-coding RNAs) with insulin resistance, accelerated senescence, and inflammation in patients with type 2 diabetes. Hum genomics. 12(1), 41 (2018)

9. Honardoost, M., Keramati, F., Arefian, E., Mohammadi Yeganeh, S. \& Soleimani M. Network of three specific microRNAs influence type 2 diabetes through inducing insulin resistance in muscle cell lines. J Cell Biochem.https://doi.org/10.1002/jcb.27381 (2018)

10. Kim, EJ., Kang, KH. \& Ju, JH. CRISPR-Cas9: a promising tool for gene editing on induced pluripotent stem cells. Korean J Intern Med. 32, 42-61 (2017)

11. Matthews DR, et al. Homeostasis model assessment: insulin resistance and beta-cell function from fasting plasma glucose and insulin concentrations in man. Diabetologia. 28, 412-419 (1985)

12. Bustin SA. et al. The MIQE Guidelines: Minimum Information for Publication of Quantitative Real-Time PCR Experiments. Clinical Chemistry. 55, 611-622 (2009)

13. Lefort, C.T. \& Kim, M. Human T Lymphocyte Isolation, Culture and Analysis of Migration In Vitro. JoVE.40 (2010)

14. Yu X. et al. Improved delivery of Cas9 protein/gRNA complexes using lipofectamine CRISPRMAX. Biotechnol Lett. 38, 919-929 (2016)

15. De Rosa S. et al. Type 2 Diabetes Mellitus and Cardiovascular Disease: Genetic and Epigenetic Links. Front Endocrinol (Lausanne). 9, 2 (2018)

16. Liu Q. et al. Different RET gene mutation-induced multiple endocrine neoplasia type 2A in 3 Chinese families. Medicine (Baltimore). 96, e5967 (2017)

17. Mathiesen JS. et al. Founder Effect of the RET ${ }^{\mathrm{C} 611 Y}$ Mutation in Multiple Endocrine Neoplasia 2A in Denmark: A Nationwide Study. Thyroid. 27, 15051510 (2017)

18. Machens, A., Lorenz, K., Weber, F. \& Dralle, H. Genotype-specific progression of hereditary medullary thyroid cancer. Hum Mutat. 39, 860-869 (2018)

19. Paratala BS. et al. RET rearrangements are actionable alterations in breast cancer. Nat Commun. 9, 4821 (2018)

20. Tan L. et al. Expression and copy number gains of the RET gene in 631 early and mid-stage non-small cell lung cancer cases. Thorac Cancer.9, $445-451$ (2018)

21. Esteves, J.V., Enguita, F.J. \& Machado, U.F. MicroRNAs-Mediated Regulation of Skeletal Muscle GLUT4 Expression and Translocation in Insulin Resistance. Journal of Diabetes Research. 2017,1-11 (2017)

22. Acharya S. et al. Downregulation of GLUT4 contributes to effective intervention of estrogen receptor-negative/HER2-overexpressing early stage breast disease progression by lapatinib. Am J Cancer Res. 6, 981-995 (2016)

23. McBrayer SK. et al. Multiple myeloma exhibits novel dependence on GLUT4, GLUT8, and GLUT11: implications for glucose transporter-directed therapy. Blood. 119, 4686-4697 (2012)

24. Cho H. et al. Insulin resistance and a diabetes mellitus-like syndrome in mice lacking the protein kinase Akt2 (PKB $\beta$ ). Science. 292, 1728-1731 (2001)

25. Caruso M. et al. Novel Endogenous, Insulin-Stimulated Akt2 Protein Interaction Partners in L6 Myoblasts. PLoS One. 10, e0140255 (2015)

26. Cheng JQ. et al. AKT2, a putative oncogene encoding a member of a subfamily of protein-serine/threonine kinases, is amplified in human ovarian carcinomas. Proc Natl Acad Sci USA. 89, 9267-9271 (1992)

27. Xu X. et al. Akt2 expression correlates with prognosis of human hepatocellular carcinoma. Oncol Rep. 11, 25-32 (2004)

28. Kirkegaard T. et al. Molecular alterations in AKT1, AKT2 and AKT3 detected in breast and prostatic cancer by FISH. Histopathology. 56, 203-211 (2010)

29. Hers, I., Vincent, EE. \& Tavaré, JM. Akt signalling in health and disease. Cell Signal. 23, 1515-1527 (2011)

30. Nigi L. et al. MicroRNAs as Regulators of Insulin Signaling: Research Updates and Potential Therapeutic Perspectives in Type 2 Diabetes. Int J Mol Sci. 19, 3705 (2018)

31. Yildirim, SS., Akman, D., Catalucci, D. \& Turan, B. Relationship between downregulation of miRNAs and increase of oxidative stress in the development of diabetic cardiac dysfunction: junctin as a target protein of miR-1. Cell Biochem Biophys. 67, 1397-1408 (2013)

32. Chen, T., Ding, G., Jin, Z., Wagner, MB. \& Yuan, Z. Insulin ameliorates miR-1-induced injury in H9c2 cells under oxidative stress via Akt activation. Mol Cell Biochem. 369, 167-174 (2012) 
33. Feng, B., Cao, Y., Chen, S., Ruiz, M. \& Chakrabarti, S. Reprint of: miRNA-1 regulates endothelin-1 in diabetes. Life Sci. 118, 275-280 (2014)

34. Li D. et al. MicroRNA-1 inhibits proliferation of hepatocarcinoma cells by targeting endothelin-1. Life Sci. 91, 440-447 (2012)

35. Nasser MW. et al. Down-regulation of micro-RNA-1 (miR-1) in lung cancer. Suppression of tumorigenic property of lung cancer cells and their sensitization to doxorubicin-induced apoptosis by miR-1. J Biol Chem. 283, 33394-33405 (2008)

36. Han C. et al. MicroRNA-1 (miR-1) inhibits gastric cancer cell proliferation and migration by targeting MET. Tumour Biol. 36, 6715-6723 (2015)

37. Wu, L., Wang, T., He, D., Li, X. \& Jiang, Y. miR-1 inhibits the proliferation of breast cancer stem cells by targeting EVI-1. Onco Targets Ther. 11, 8773-8781 (2018)

38. Su, L., Han, D., Wu, J. \& Huo, X. Skp2 regulates non-small cell lung cancer cell growth by Meg3 and miR-3163. Tumour Biol.37, 3925-3931 (2016)

39. Jia, M., Wei, Z., Liu, P. \& Zhao, X. Silencing of ABCG2 by MicroRNA-3163 Inhibits Multidrug Resistance in Retinoblastoma Cancer Stem Cells. J Korean Med Sci. 31, 836-842 (2016)

40. Zhou Y. et al. Ginsenoside 20(S)-Rg3 Inhibits the Warburg Effect Via Modulating DNMT3A/ MiR-532-3p/HK2 Pathway in Ovarian Cancer Cells. Cell Physiol Biochem. 45, 2548-2559 (2018)

41. Wang L. et al. Long Noncoding RNA (IncRNA)-Mediated Competing Endogenous RNA Networks Provide Novel Potential Biomarkers and Therapeutic Targets for Colorectal Cancer. Int J Mol Sci. 20, 5758 (2019)

42. Kamel MM. et al. Investigation of long noncoding RNAs expression profile as potential serum biomarkers in patients with hepatocellular carcinoma. Translational Research. 168, 134-145 (2016)

43. Chakraborty, C., Doss, CG., Bandyopadhyay, S. \& Agoramoorthy, G. Influence of miRNA in insulin signaling pathway and insulin resistance: micromolecules with a major role in type-2 diabetes. Wiley Interdiscip Rev RNA. 5, 697-712 (2014)

44. De Meyts, P. \& Whittaker, J. Structural biology of insulin and IGF1 receptors: implications for drug design. Nat Rev Drug Discov. 1, 769-783 (2002)

45. Sachdev, D. et al. A chimeric humanized single-chain antibody against the type 1 insulin-like growth factor (IGF) receptor renders breast cancer cells refractory to the mitogenic effect of IGF-1. Cancer Res. 63, 627-635 (2003)

46. Adachi, Y. et al. Effects of genetic blockade of the insulin-like growth factor receptor in human colon cancer cell lines. Gastroenterology. 123, 1191-1204 (2002)

47. Burfeind, P., Chernicky, CL., Rininsland, F., Ilan, J. \& Ilan, I. Antisense RNA to the type I insulin-like growth factor receptor suppresses tumor growth and prevents invasion by rat prostate cancer cells in vivo. Proc Natl Acad Sci. 93, 7263-7268 (1996)

48. Zhang, H., Pelzer, AM., Kiang, DT. \& Yee, D. Downregulation of type I insulin-like growth factor receptor increases sensitivity of breast cancer cells to insulin. Cancer Res. 67, 391-397 (2007)

49. Das, A., Reis, F., Maejima, Y., Cai, Z. \& Ren, J. mTOR Signaling in Cardiometabolic Disease, Cancer, and Aging. Oxid Med Cell Longev. 2017, 6018675 (2017)

50. Khan KH. et al. Hyperglycemia and Phosphatidylinositol 3-Kinase/Protein Kinase B/Mammalian Target of Rapamycin (PI3K/AKT/mTOR) Inhibitors in Phase I Trials: Incidence, Predictive Factors, and Management. Oncologist. 21, 855-860 (2016)

51. Pópulo, H., Lopes, JM. \& Soares, P. The mTOR signalling pathway in human cancer. Int J Mol Sci. 13, 1886-1918 (2012)

52. Cai, H., Dong, LQ. \&Liu, F. Recent Advances in Adipose mTOR Signaling and Function: Therapeutic Prospects. Trends Pharmacol Sci. 37, 303-317 (2016)

53. Sciarretta, S., Volpe, M. \& Sadoshima, J. Mammalian target of rapamycin signaling in cardiac physiology and disease. Circ Res.114, 549-564 (2014)

54. Francois A. et al. The mTOR Signaling Pathway in Neurodegenerative Diseases. Molecules to Medicine with mTOR. 85-104. (2016)

\section{Figures}



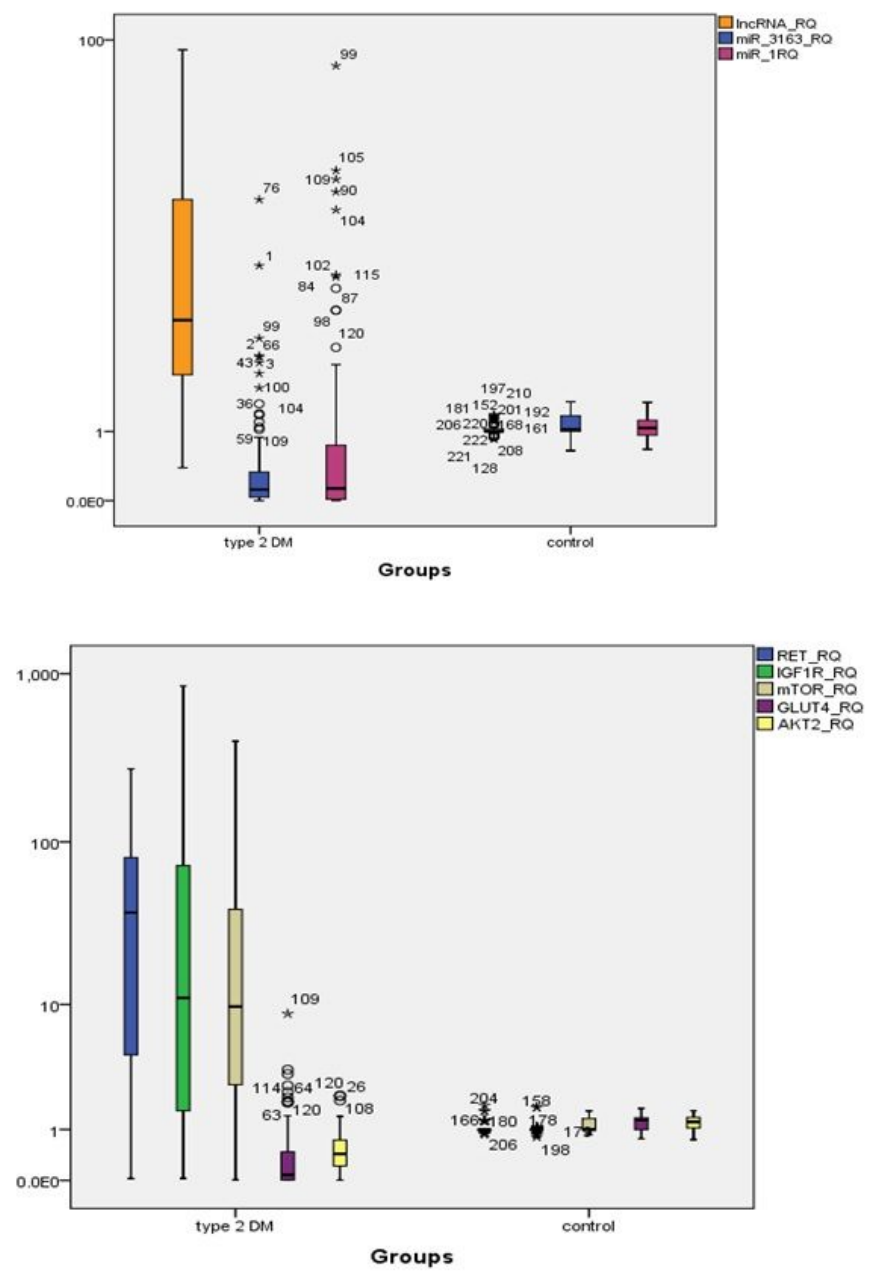

Figure 1

(1a): BOXPLOT showing differential expression of LncRNA-RP11-773H22.4, miR-3163 and miR-1 miRNAs as determined by qRT-PCR in the investigated groups. (1b): BOXPLOT showing differential expression of RET, IGF1-R, m-TOR, GLUT-4 and AKT2 as determined by qRT-PCR in the investigated groups 

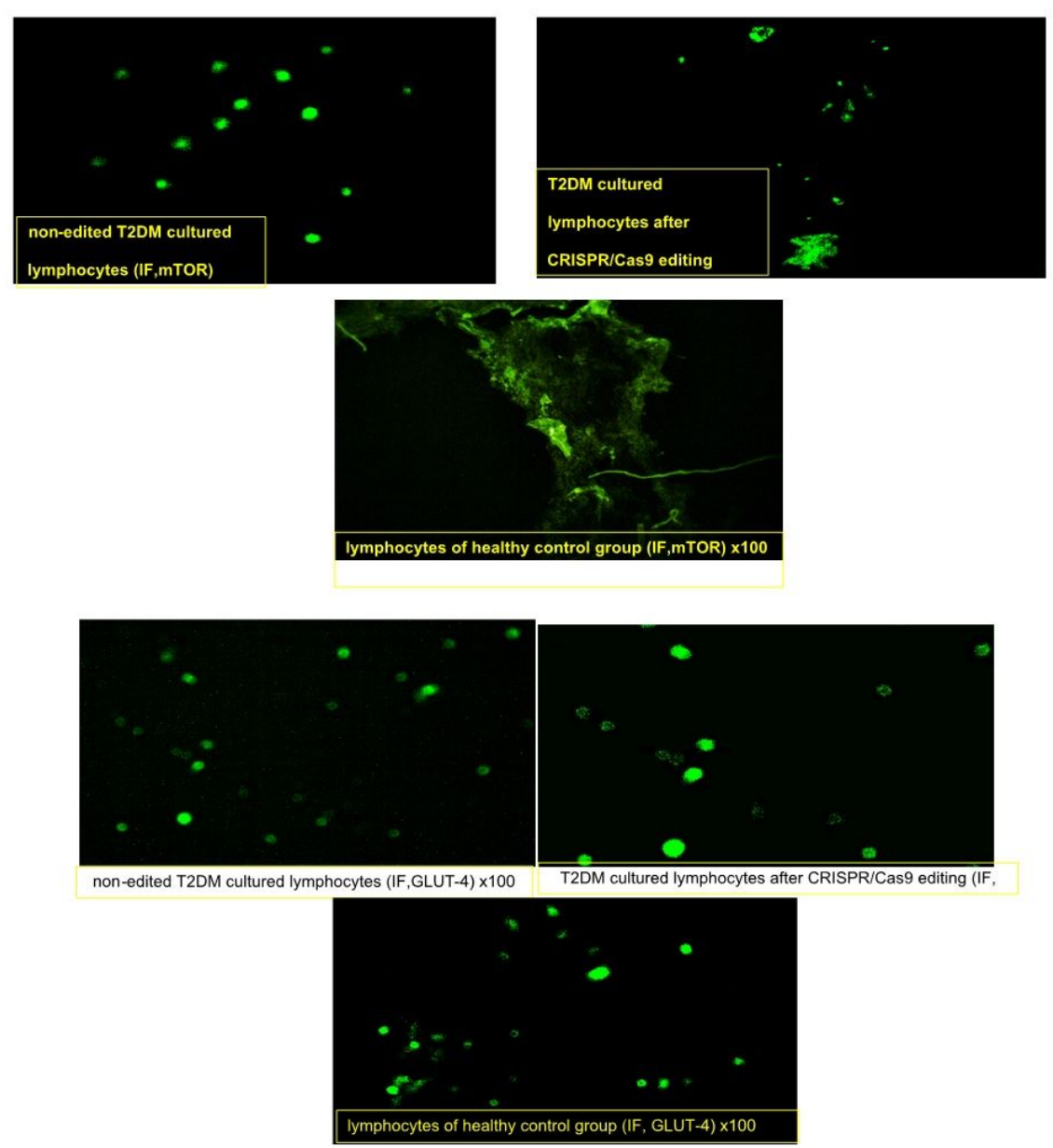

Figure 2

(2a): Immunofluorescence assay staining of lymphocytes cultured cells with specific polyclonal antibodies against mammalian target of rapamycin ( $\mathrm{m}$-TOR) protein. (2b): Immunofluorescence assay staining of lymphocytes cultured cells with specific polyclonal antibodies against solute carrier family 2 (facilitated glucose transporter), member 4 (GLUT4) protein

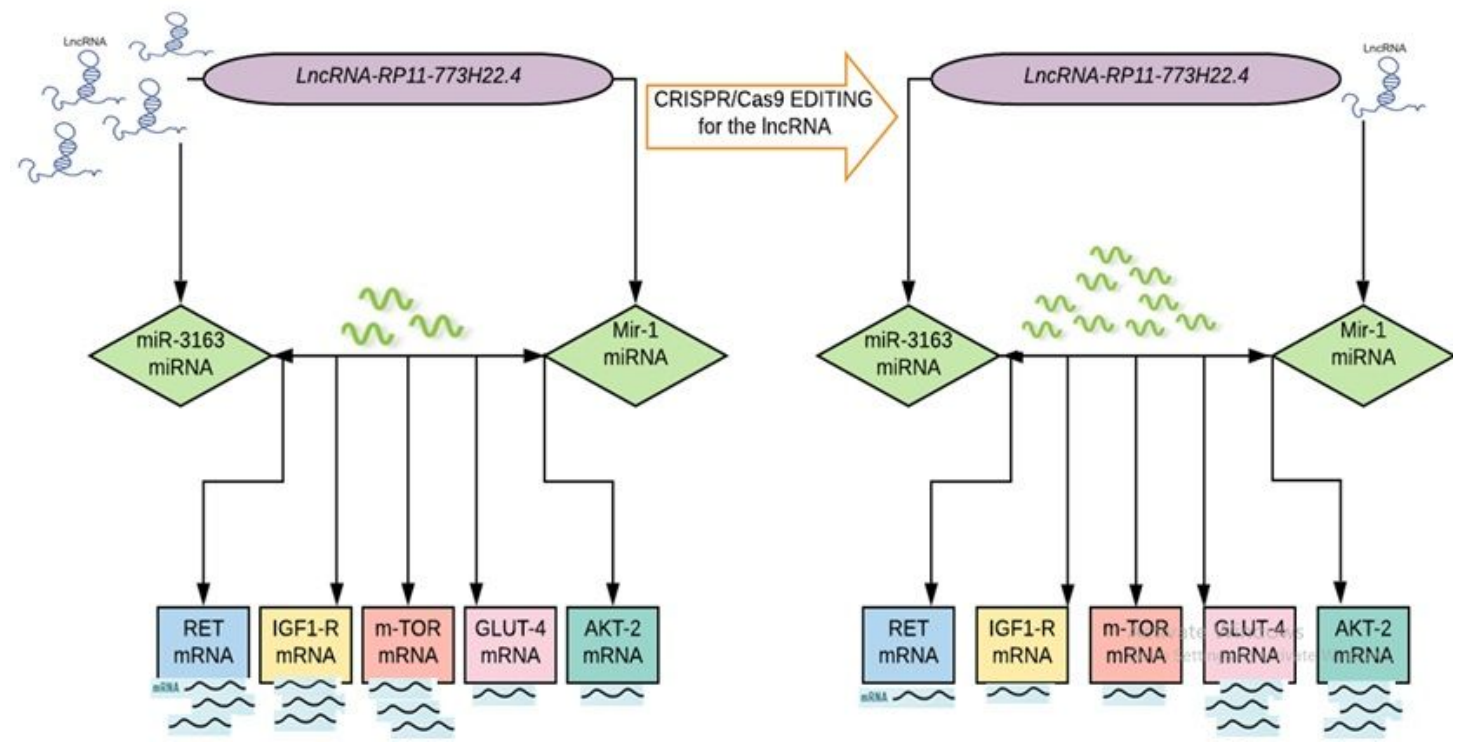

Figure 3

Proof of concept of ceRNA hypothesis in IR in T2DM 


\section{Supplementary Files}

This is a list of supplementary files associated with this preprint. Click to download.

- supplementarymaterial.docx

- GraphicalAbstract.jpg 